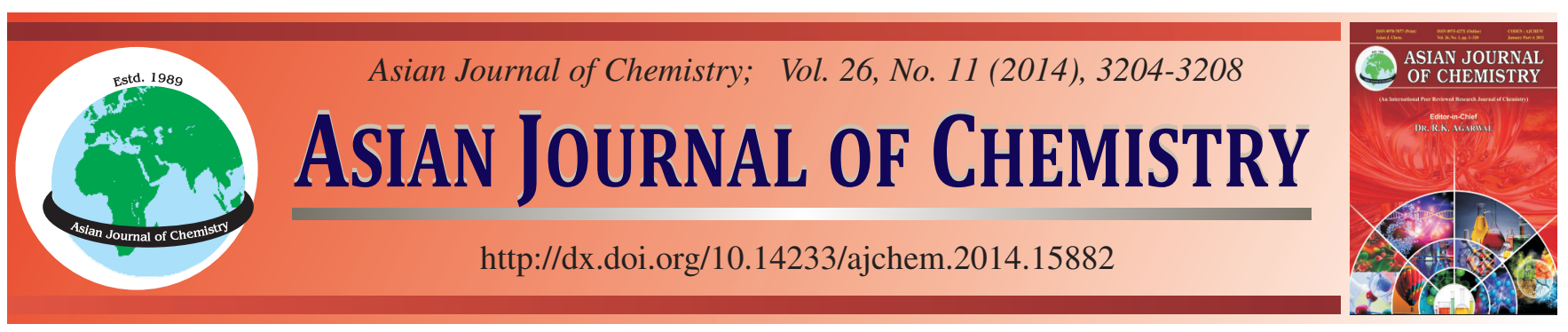

\title{
Removal of Carbon Dioxide from Biogas with Pilot Chemical Absorption System at Different Operating Conditions
}

\author{
Y. XIAO* and X. LI
}

Centre for Resources and Environmental Research, Beijing University of Chemical Technology, Beijing, P.R. China

*Corresponding author: Fax: +86 10 80105121; Tel: +86 10 64435161; E-mail: xiaoyong@ mail.buct.edu.cn

\begin{abstract}
In this work, a large amount of removal of carbon dioxide from biogas could be achieved on a pilot absorption system using monoethanolamine solution as an absorbent. The important parameters influencing on the $\mathrm{CO}_{2}$ removal were investigated. The optimized $\mathrm{CO}_{2}$ removal efficiency could be achieved at the monoethanolamine solution flow of $20 \mathrm{~L} \mathrm{~h}^{-1}$ and the gas flow of $350 \mathrm{~L} \mathrm{~h}^{-1}$ when the volume of $\mathrm{CO}_{2}$ was $45 \%$. The purity of biogas of the resulting gas could be as high as 97-100\%. Moreover, the $\mathrm{CO}_{2}$ removal efficiency reduced with increasing $\mathrm{CO}_{2}$ content of the input gas. The pressure in the absorption tower varying in $0.05 \mathrm{MPa}$ to $0.1 \mathrm{MPa}$ has no significant influence on the $\mathrm{CO}_{2}$ removal. The $\mathrm{CO}_{2}$ removal efficiency could be improved when the volume of the input $\mathrm{CO}_{2}$ was reduced or the content of the monoethanolamine was increased.
\end{abstract}

Keywords: Carbon dioxide, Monoethanolamine, Absorption, Regeneration, Mixed gas.

\section{INTRODUCTION}

Nowadays, with the growth of environmental pollutions and energy crisis, the development of clean and renewable energy has received great deals of attention in both the scientific and technological fields ${ }^{1}$. As an important biomass energy, the use of biogas can not only reduce the discharge of the house refuse, city sludge and other waste, but also it can play a positive role in the remission of the severe "greenhouse gas"2. Although the technologies of anaerobic digestion for biogas production in China have gradually been in mature, the use of the biogas still remains in its original ways ${ }^{3,4}$. Normally, the biogas resources are mainly used for living energy for the rural families with low efficiency ${ }^{5,6}$. Therefore, the high value and efficient utilization of the biogas has not been achieved. Theoretically, the application of the biogas can be used efficently including vehicle fuel, fuel cell besides heating and cooking as an energy source ${ }^{7-9}$.

Moreover, the calorific value of biogas is in the range of $22000-25000 \mathrm{~kJ} \mathrm{~m}^{-3}$. As one of main components ${ }^{10}$, calorific value of methane is as high as $39000 \mathrm{~kJ} \mathrm{~m}^{-3}$. Therefore, it is necessary to purify the biogas to maximize the utilization efficiency of biogas. As for the biogas purification, removal of $\mathrm{CO}_{2}$ is the first and the most important step. Furthermore, in recent years, the effective separation and regeneration of $\mathrm{CO}_{2}$ also became important for the recycling and utilization of energy ${ }^{11}$. Although great efforts ${ }^{12-16}$ have been devoted to design and develop new physical and chemical methods to increase absorption of $\mathrm{CO}_{2}$. Generally, there are three methods to separate $\mathrm{CO}_{2}$ from the biogas ${ }^{17}$. One is water treatment, whereas such method needs complicated operating conditions and cannot usually achieve a high level separation ${ }^{18}$. The second one is membrane separation method which suffers high cost and short lifetime of membrane ${ }^{19-20}$. The third one is PressureSwing-Adsorption method involving a physical absorption process, which is beneficial to the environment ${ }^{21}$.

However, this method also needs complicated equipments. Therefore, it is prime importance to find an effective method to achieve an easy, safe and stable process for a large scale separation with low cost. As comparison, the chemical absorption method can run in low costs with high stability and security and potentially overcome the above difficulties in the mentioned methods.

In this work, we have put forward new designed equipment, which could separate a large amount of $\mathrm{CO}_{2}$ from simulated biogas and regenerate absorption solution effectively. The removal of $\mathrm{CO}_{2}$ was investigated on this pilot system at various parameters including the gas flow, liquid flow, pressure, initial $\mathrm{CO}_{2}$ content, monoethanolamine content and absorption tower height. The aims of this work are to clarify the effects of the mentioned parameters on the $\mathrm{CO}_{2}$ removal, which could offer a theoretical reference for the biogas purification in application. 


\section{EXPERIMENTAL}

In order to simplify the experiments on the $\mathrm{CO}_{2}$ removal, $\mathrm{N}_{2}$ was used to take place of methane, which was further mixed with $\mathrm{CO}_{2}$ in a certain ratio to simulate the biogas. Because the solubility of $\mathrm{N}_{2}$ in the water is very small, the whole process could be more accurately described for the gas purification.

We designed a pilot-scale plant which contained an absorption tower (height $260 \mathrm{~cm}$ ), a desorption tower (height 190 $\mathrm{cm}$ ) and two liquid storage tanks (40 L for each) (Fig. 1). The inner and outer diameters for both of absorption tower and desorption tower, both were $46 \mathrm{~mm}$ and $50 \mathrm{~mm}$, respectively. There were four wall wiper redistributing sets which were welded in the inner wall of the absorption tower and desorption tower to avoid the liquid wall flowing. Two types of stainless steel $\theta$-rings (height of $4 \mathrm{~mm}$ with diameter of $4 \mathrm{~mm}$ and height of $6 \mathrm{~mm}$ with diameter of $6 \mathrm{~mm}$ ) were filled in both the absorption tower and desorption tower to create a large surface between gas and liquid. Specially, the $\theta$-rings with height of $6 \mathrm{~mm}$ were filled in the every wall wiper redistributing sets to make the reaction of liquid and gas effectively. The heat insulation layer (thickness of $40 \mathrm{~mm}$ ) was covered around the desorption tower through the electricity relay control to ensure the desorption temperature constant. The condense unit was stalled at the top of desorption tower for condensing absorption liquid steam. The electric heating device was stalled at the bottom of desorption tower for heating the absorption liquid. We designed a preheating equipment before the desorption tower to raise the temperature of absorption liquid and make the process of the desorption process much easier.

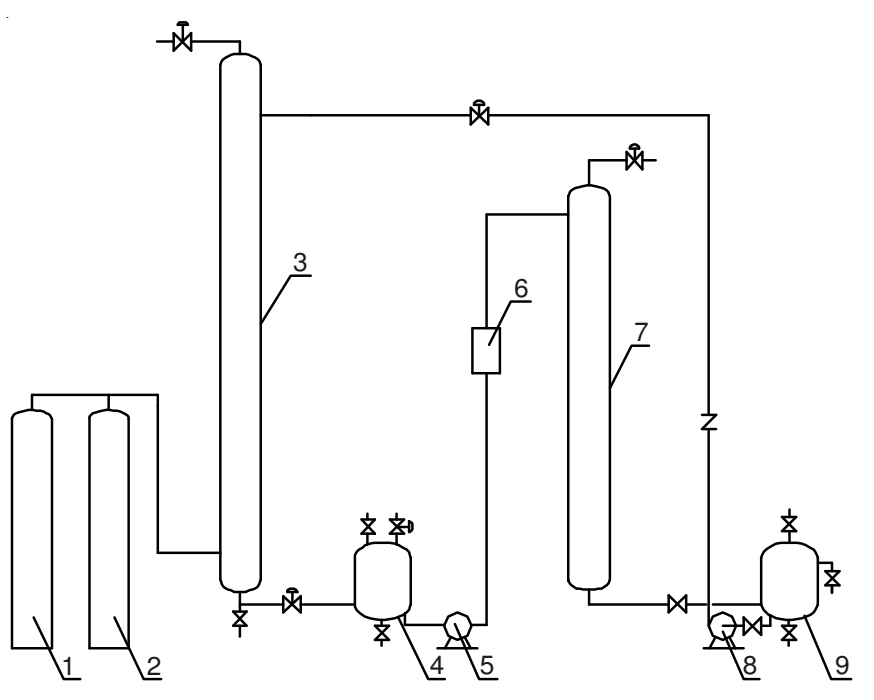

Fig. 1. Equipments for the absorption of $\mathrm{CO}_{2}$ from the mixed gas by the chemical method (1. $\mathrm{CO}_{2}$ cylinder $2 . \mathrm{N}_{2}$ cylinder 3 . Absorption tower 4. Lean solution storage tank 5. Pump1. 6. Preheating equipment 7. Desorption tower 8. Pump 29. Rich solution storage tank)

The $\mathrm{CO}_{2}$ gas $(99.99 \%)$ and the $\mathrm{N}_{2}$ gas $(99.99 \%)$, were both purchased from Beijing Orient Medical Gas Co. Ltd.. They were mixed as simulated biogas before being transferred to the absorption tower. The simulated biogas and absorption liquid were then channeled into the absorption tower with a stable pressure. The absorption liquid used in the process was monoethanolamine solution which was sprayed from the top of the absorption tower. monoethanolamine was purchased from Tianjin Fuchen Chemical Reagents Factory. The mixed gas was channeled from the bottom of the tower. After the absorption, the monoethanolamine solution was pumped into the preheating equipment, then pumped into the desorption tower. In this tower, the monoethanolamine solution was regenerated in the conditions of the pressure of $50 \mathrm{kPa}$ and the temperature of $95 \pm 5^{\circ} \mathrm{C}$. The surplus gas was released from the tower.

General procedure: According to the actual content of $\mathrm{CO}_{2}$ in the biogas, the volume fraction of $\mathrm{CO}_{2}$ in the simulated biogas was controlled at 25, 35 and $45 \%$. Based on the experimental conditions, the pressure in the absorption tower was controlled in the range from 0.05 to $0.1 \mathrm{MPa}$. The liquid flow of $30 \mathrm{~L} \mathrm{~h}^{-1}$ and the gas flow of $590 \mathrm{~L} \mathrm{~h}^{-1}$ were the maximum operating flows for this system. Therefore, the gas inflow in the absorption tower was controlled in the range $230-590 \mathrm{~L} \mathrm{~h}^{-1}$ and the flow of absorption solution was in the range of 15-30 $\mathrm{L} \mathrm{h}^{-1}$. The volume fractions of monoethanolamine were selected as 5,10 and $20 \%$ in the absorption solution. The monoethanolamine solution with the absorbed $\mathrm{CO}_{2}$ was heated up to $90^{\circ} \mathrm{C}$ in the desorption tower, for regeneration. In this system, a closed monoethanolamine solution cycle was applied in order to protect the environment and to save the energy and monoethanolamine consumption.

Detection method: The gas samples were taken from the inlet and outlet of the system. The purified gas was obtained from the pilot-plant without drying. We used a syringe to get gas samples, then put them into the gas chromatograph (GC) (SP-2100, Beifen Ruili Co., Beijing) which equipped with a $2 \mathrm{~m} \times 3 \mathrm{~mm}$ stainless-steel column and a thermal conductivity detector (TCD) to measure the content of $\mathrm{N}_{2}$ and $\mathrm{CO}_{2}$. The temperatures of oven, injector and detector were controlled at 100, 120 and $120^{\circ} \mathrm{C}$, respectively. Argon was used as the carrier gas at a flow rate of $30 \mathrm{~mL} / \mathrm{min}$. The standard gas (Beifen Ruili Co., Beijing) composed of $60.1 \% \mathrm{~N}_{2}$ and $39.9 \%$ $\mathrm{CO}_{2}$ was used for the calibration .

\section{RESULTS AND DISCUSSION}

Effect of the ratio of liquid/gas: Herein, we set the flow of monoethanolamine solution as $15 \mathrm{~L} \mathrm{~h}^{-1}, 20 \mathrm{~L} \mathrm{~h}^{-1}, 25 \mathrm{~L} \mathrm{~h}^{-1}$ and $30 \mathrm{~L} \mathrm{~h}^{-1}$. The pressure in the absorption tower was fixed at $0.1 \mathrm{MPa}$ and the $\mathrm{CO}_{2}$ content in the simulated biogas was selected as $45 \%$. The gas flow was in the range of $230-590 \mathrm{~L}$ $\mathrm{h}^{-1}$. The height of the absorption tower was $2.6 \mathrm{~m}$. The $\mathrm{CO}_{2}$ removal ratio with the change of the ratio of liquid/gas was illustrated in Fig. 2. When the monoethanolamine solution flow was in the range of $15-25 \mathrm{~L} \mathrm{~h}^{-1}$, the $\mathrm{CO}_{2}$ removal ratio decreased as the gas flow increasing. With increasing the flow of the monoethanolamine solution, the $\mathrm{CO}_{2}$ removal ratio significantly increase. Taking the condition of the gas of $530 \mathrm{~L} \mathrm{~h}^{-1}$ as an example, when the monoethanolamine solution flow increased from $15 \mathrm{~L} \mathrm{~h}^{-1}$ to $20 \mathrm{~L} \mathrm{~h}^{-1}$, the $\mathrm{CO}_{2}$ removal ratio was increased at $98 \%$. When the flow increased to $25 \mathrm{~L} \mathrm{~h}^{-1}$, the content of $\mathrm{CO}_{2}$ was reduced by $21.3 \%$. When the flow was $30 \mathrm{~L} \mathrm{~h}^{-1}$, the $\mathrm{CO}_{2}$ could be totally removed under the condition of the gas flow of 230-590 $\mathrm{L} \mathrm{h}^{-1}$. 

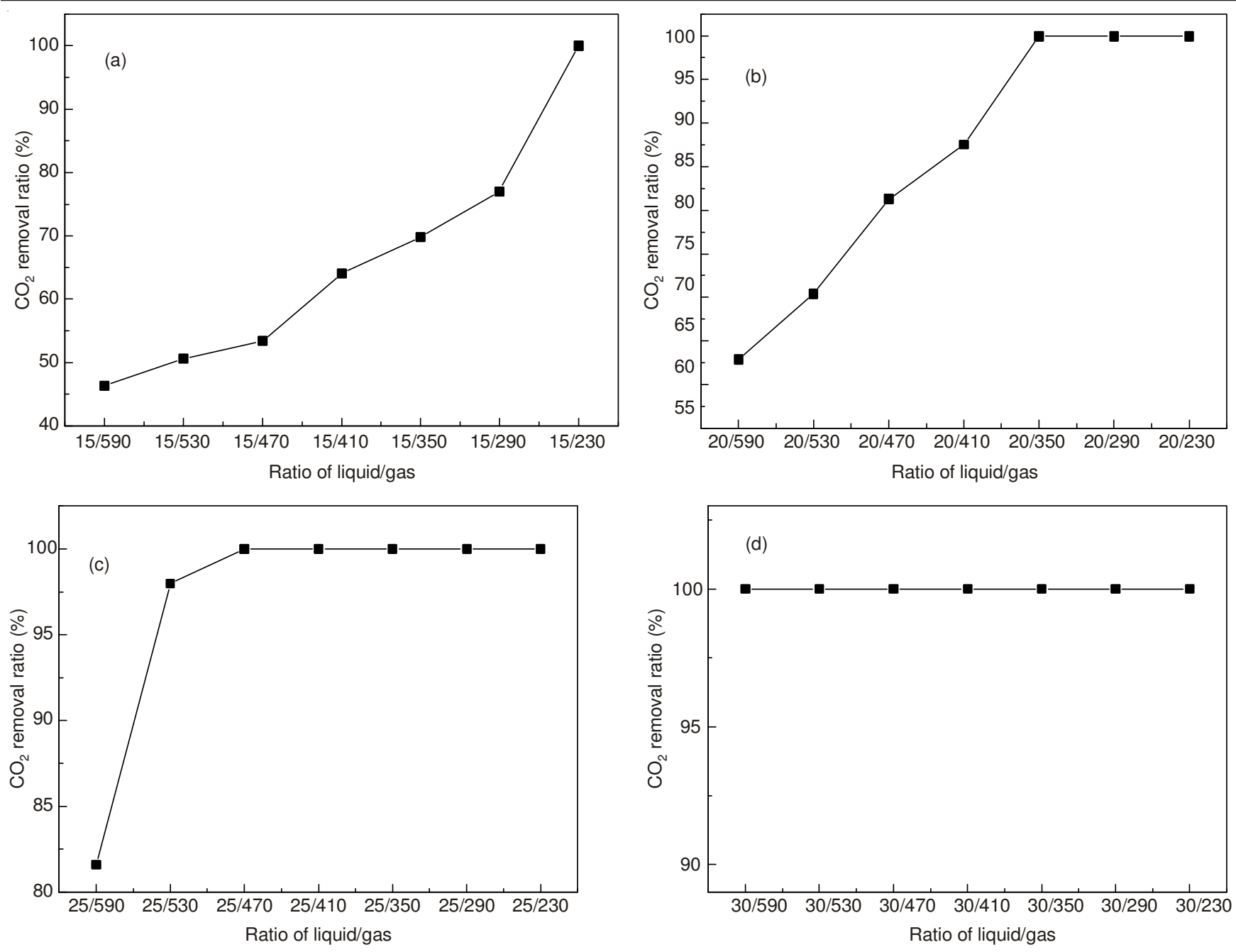

Fig. 2. $\mathrm{CO}_{2}$ removal ratio with different ratio of liquid/gas

According to Fig. 2, it could be obviously found that the $\mathrm{CO}_{2}$ removal ratio could be increased with the increase of the ratio of liquid/gas. It could be increased from 62.9 to $100 \%$ when the liquid/gas ratio varied from $20 / 590$ to $20 / 350$. When the liquid/gas ratio was in the range of 20/350-20/230 $\mathrm{L} \mathrm{h}^{-1}$, the $100 \% \mathrm{CO}_{2}$ removal ratio could be achieved.

When the flow of the input gas was reduced to $350 \mathrm{~L} \mathrm{~h}^{-1}$, the $100 \% \mathrm{CO}_{2}$ removal ratio also could be achieved. Considering the flow of the input gas was less than $350 \mathrm{~L} \mathrm{~h}^{-1}$ in practical process, we kept the flow of the input gas at the range of 230-350 $\mathrm{L} \mathrm{h}^{-1}$. It was found that the $\mathrm{CO}_{2}$ removal ratio could keep at $100 \%$ for three months, which demonstrated the method was highly effective for absorption of $\mathrm{CO}_{2}$ for applications.

Effects of pressures in the absorption tower: All of the experiments above were performed with the constant pressure in the absorption tower of $0.1 \mathrm{MPa}$. To study the influence of the pressure in the absorption tower on the $\mathrm{CO}_{2}$ absorption, we further adjusted the pressure to $0.05,0.075$ and $0.1 \mathrm{MPa}$. The gas flow rate, monoethanolamine solution flow rate and the $\mathrm{CO}_{2}$ content were controlled at $350 \mathrm{~L} \mathrm{~h}^{-1}, 20 \mathrm{~L} \mathrm{~h}^{-1}$ and $45 \%$, respectively. The results are shown in Fig. 3. As the pressure of the absorption tower decreased from 0.1 to $0.05 \mathrm{MPa}$, the $100 \% \mathrm{CO}_{2}$ removal ratio could be kept. Thus it is concluded that the pressure of the absorption tower was not a key factor to affect the $\mathrm{CO}_{2}$ removal efficiency.

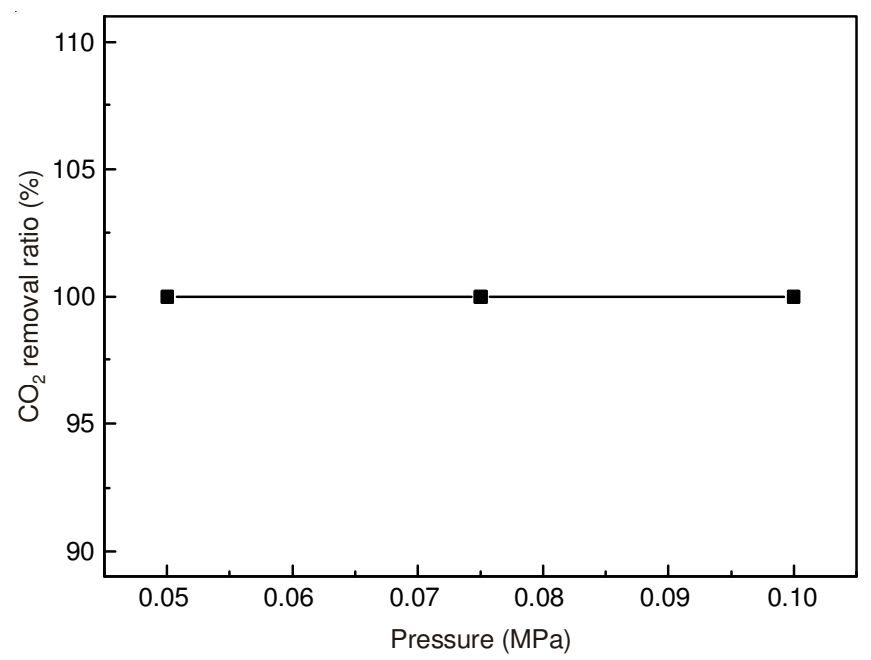

Fig. 3. $\mathrm{CO}_{2}$ removal ratio with different pressure

Effects of the initial $\mathrm{CO}_{2}$ content: For the practice, it is necessary to investigate the $\mathrm{CO}_{2}$ absorption effects once the input $\mathrm{CO}_{2}$ content changed. According to the composition of the real biogas, we set the initial $\mathrm{CO}_{2}$ content in the range of 
$25-45 \%$. The flow of the monoethanolamine solution was 20 $\mathrm{L} \mathrm{h}^{-1}$ and the gas flow was in the range $230-590 \mathrm{~L} \mathrm{~h}^{-1}$. Fig. 4 presented the $\mathrm{CO}_{2}$ removal ratio at different $\mathrm{CO}_{2}$ concentration. It was shown that the $\mathrm{CO}_{2}$ removal ratio presented increase with the decease of the initial $\mathrm{CO}_{2}$ content when the liquid/ gas ratio was lower than 20/350. When the liquid/gas ratio was 20/530, the initial $\mathrm{CO}_{2}$ content increased from 25 to $35 \%$, the $\mathrm{CO}_{2}$ removal ratio was decreased by $15.8 \%$. When the initial $\mathrm{CO}_{2}$ content kept increasing from 35 to $45 \%$, the $\mathrm{CO}_{2}$ removal ratio was correspondingly decreased by $13.8 \%$. Therefore, it could be concluded that the input $\mathrm{CO}_{2}$ concentration played a key role to the $\mathrm{CO}_{2}$ removal efficiency by using the monoethanolamine solution as the absorbent.

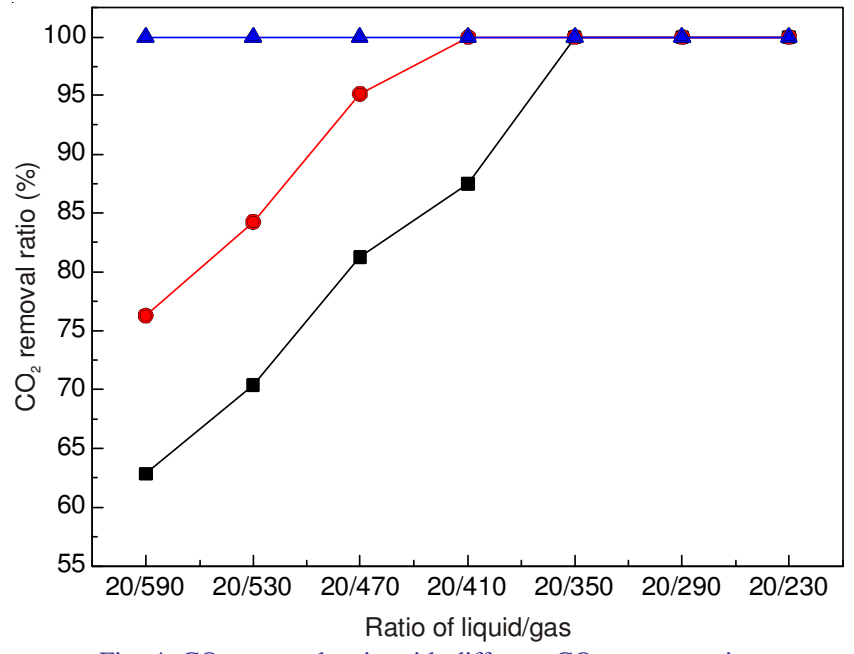

Fig. 4. $\mathrm{CO}_{2}$ removal ratio with different $\mathrm{CO}_{2}$ concentration

Effects of the content of the monoethanolamine: According to literatures ${ }^{22}$, the concentration of the monoethanolamine was usually in the range of 5 to $15 \%$. Once the concentration increased to more than $15 \%$, the absorption efficiency decreased and the equipment was potentially corroded. If the concentration was less than $5 \%$, the absorption was not obvious. Therefore, we set the concentration of monoethanolamine of 5,10 and $15 \%$ to investigate their influences on the $\mathrm{CO}_{2}$ absorption efficiency. As shown in Fig. 5, increasing concentration of monoethanolamine, the $\mathrm{CO}_{2}$ removal ratio was correspon-

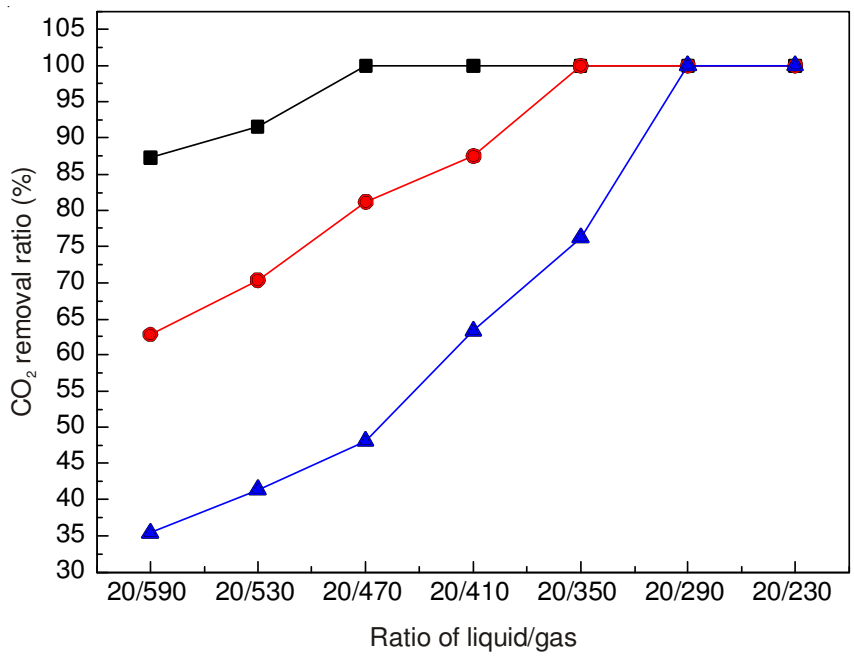

Fig. 5. $\mathrm{CO}_{2}$ removal ratio with different monoethanolamine concentration dingly increased. When the liquid/gas ratio was kept constant at $20 / 470$, the $\mathrm{CO}_{2}$ removal ratio increased by $33.1 \%$ and $18.7 \%$ as the concentration of the monoethanolamine solution increased from 5 to $10 \%$ and $15 \%$.

Effects of the padding layer height in the absorption tower: Due to other researchers' work ${ }^{23}$, there was no need to build a high absorption tower when using the chemical absorption method. We further investigated the $\mathrm{CO}_{2}$ absorption efficiency when the height of the absorption tower was reduced by $0.7 \mathrm{~m}$. Taking the condition with the liquid/gas ratio of 20/ 410 as an example, the $\mathrm{CO}_{2}$ removal ratio could be decreased by $20.6 \%$ once the height of the padding layer in absorption tower was reduced by $0.7 \mathrm{~m}$ (Fig. 6). This result suggested that the height of the padding layer was important to the $\mathrm{CO}_{2}$ removal efficiency.

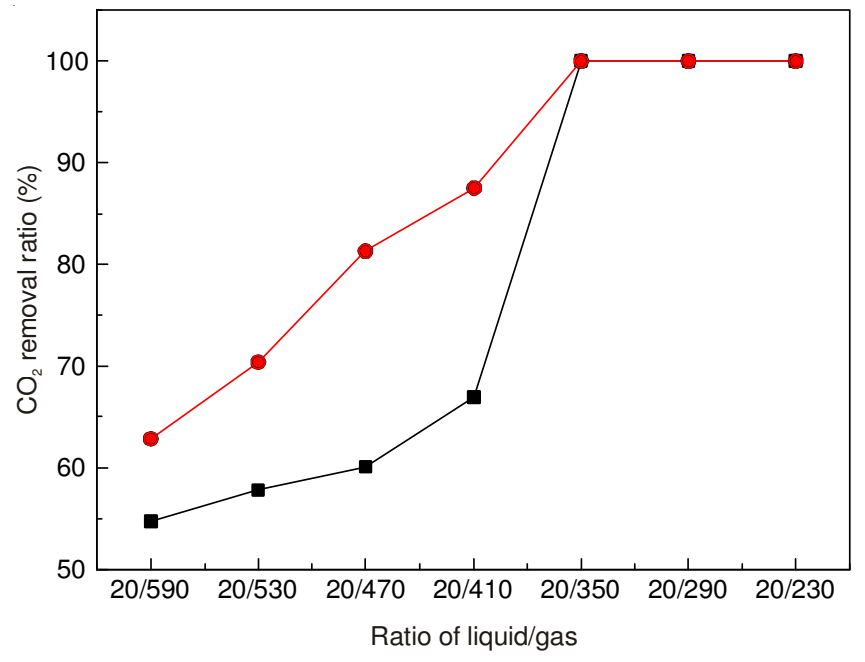

Fig. 6. $\mathrm{CO}_{2}$ removal ratio with different absorption tower height

\section{Conclusion}

In this work, the absorption of $\mathrm{CO}_{2}$ in the simulated biogas was investigated at the pilot system by the use of monoethanolamine as the chemical absorbent. The main parameters influencing on the $\mathrm{CO}_{2}$ removal were investigated. The results indicated that increasing initial $\mathrm{CO}_{2}$ content, the $\mathrm{CO}_{2}$ removal efficiency could be reduced. The optimized efficiency occurred at the liquid/gas ratio of 20/350, when the initial $\mathrm{CO}_{2}$ content was $45 \%$. It was also found that the pressure in the absorption tower in the range of $0.05 \mathrm{MPa}-0.1 \mathrm{MPa}$ had no obvious influence on the $\mathrm{CO}_{2}$ removal. Meanwhile, the $\mathrm{CO}_{2}$ removal could be improved once the volume of the input $\mathrm{CO}_{2}$ was reduced. The $\mathrm{CO}_{2}$ removal could be significantly increased with the increase of monoethanolamine content. Finally, increasing the height of absorption tower was also benefit to the removal efficiency. In summary, the work supplied a good method to absorb a large amount of $\mathrm{CO}_{2}$ in the biogas.

\section{ACKNOWLEDGEMENTS}

The work was financially supported by the National "863" Project of China (No. 2008AA062401/02) and the International Cooperation Project (No. 2011DFA90800). 


\section{REFERENCES}

1. S. Chu, Science, 325, 1599 (2009).

2. Y. Pang and X. Li, Trans. Chinese Soc. Agric. Eng., 22(S1), 53 (2006).

3. X. Jiang, S.G. Sommer and K.V. Christensen, Sustainab. Biofuels, 39, 6073 (2011).

4. X. Li, B. Zhou and H. Yuan, Trans. Chinese Soc. Agric. Eng., S2, 352 (2011).

5. X.J. Li, Solid Waste Engineering, China Environmental Science Press, Beijing (2003)

6. H. Katuwal and A.K. Bohara, Renew. Sustain. Energy Rev., 13, 2668 (2009).

7. J.L. Walsh, C.C. Ross, M.S. Smith and S.R. Harper, Biomass, 20, 277 (1989).

8. M.H. Praß1, Biogas Purification and Assessment of the Natural Gas Grid in Southern and Eastern Europe, Leibnitz (2008).

9. A. Wellinger and A. Lindberg, IEA Bioenergy Task 24: Biogas Upgrading and Utilization (2006).

10. X.J. Yao and Y.S. Tian, Clean Conversion of Biomass Resource Utilization Technology, Chemical Industry Press, Beijing (2005).
11. IPCC, Carbon dioxide Capture and Storage, Cambridge, Cambridge University Press, United Kingdom (2005).

12. A. Aroonwilas, P. Tontiwachwuthikul and A. Chakma, Sep. Purif. Technol., 24, 403 (2001).

13. S. Rasi, J. Läntelä, A. Veijanen and J. Rintala, Waste Manage., 28, 1528 (2008).

14. H. Xu and L. Cui, Environ. Sci. Manage., 31, 79 (2006).

15. S. Yan and M. Fang, Chem. Ind. Eng. Progr., 25, 1018 (2006).

16. Q.Y. Zeng, Y.J. Bai and C.J. Yang, Gas Chem., 35, 23 (2010).

17. A. Kohl and R. Nielsen, Gas Purification, Gulf Publishing Company, Houston, Texas (1997).

18. J. Läntelä, S. Rasi, J. Lehtinen and J. Rintala, Appl. Energy, 92, 307 (2012).

19. R. Wang, D.F. Li and D.T. Liang, Chem. Eng. Process., 43, 849 (2004).

20. P.H. Feron and A.E. Jansen, Sep. Purif. Technol., 27, 231 (2002).

21. L. Tian, Z. Deng and Z. Xia, Environ. Eng., 28, 78 (2010).

22. S.Y. Zhu, The Environmental and Industrial Gas Purification Technology, Chemical Industry Press, Beijing (2001).

23. J.T. Yeh, H.W. Pennline and K.P. Resnik, Energy Fuels, 15, 274 (2001). 